\title{
In vivo hepatitis B virus-neutralizing activity of an anti-HBsAg humanized antibody in chimpanzees
}

\author{
Se Ho Kim ${ }^{1}$, Han Kyu Oh ${ }^{1,3}$, Chun Jeih Ryu ${ }^{2,4}$, \\ Song Yong Park ${ }^{1}$ and Hyo Jeong Hong ${ }^{2,5}$
}

${ }^{1}$ Green Cross Corp.

Yongin 446-799, Korea

${ }^{2}$ Therapeutic Antibody Research Center

Korea Research Institute of Bioscience and Biotechnology

Daejeon 305-333, Korea

${ }^{3}$ Neurotech Pharmaceuticals

Seongnam 462-807, Korea

${ }^{4}$ The Department of Bioscience and Biotechnology

Sejong University

Seoul 143-747, Korea

${ }^{5}$ Corresponding author: Tel, 82-42-860-4122;

Fax, 82-42-860-4597; E-mail, hjhong@ kribb.re.kr

Accepted 7 January 2008

Abbreviations: anti-HBc, anti-HBcAg; anti-HBs, anti-HBsAg CDRs, complementarity determining regions; FRs, framework regions; $\mathrm{HBIG}$, hepatitis B immune globulin; $\mathrm{HBcAg}$, hepatitis B virus core antigen; $\mathrm{HBsAg}$, hepatitis $B$ virus surface antigen

\begin{abstract}
Previously, we constructed a humanized antibody (HuS10) that binds to the common a antigenic determinant on the S protein of HBV. In this study, we evaluated its HBV-neutralizing activity in chimpanzees. A study chimpanzee was intravenously administered with a single dose of HuS10, followed by intravenous challenge with the adrsubtype of HBV, while a control chimpanzee was only challenged with the virus. The result showed that the control chimpanzee was infected by the virus, and thus serum HBV surface antigen (HBsAg) became positive from the $14^{\text {th }}$ to $20^{\text {th }}$ week and actively acquired serum anti-HBc and anti-HBs antibodies appeared from the $19^{\text {th }}$ and $23^{\text {rd }}$ week, respectively. However, in the case of the study chimpanzee, serum HBsAg became positive from the $34^{\text {th }}$ to $37^{\text {th }}$ week, while actively acquired serum anti-HBc and anti-HBs antibodies appeared from the $37^{\text {th }}$ and $40^{\text {th }}$ week, respectively, indicating that HuS10 neutralized the virus in vivo and thus delayed the HBV infection. This novel humanized antibody will be useful in the immunoprophylaxis of $\mathrm{HBV}$ infection.
\end{abstract}

Keywords: antibodies, monoclonal; hepatitis B surface antigens; hepatitis B virus; Pan troglodytes; immunization, passive; immunotherapy

\section{Introduction}

HBV infection is a worldwide public health problem affecting 300 million persistent chronic carriers having a high risk to develop hepatocellular carcinoma (Tiollais and Buendia, 1991). For the prevention or post-exposure prophylaxis of HBV infection, hepatitis B immune globulin (HBIG) prepared from pooled human anti-HBsAg plasma is administered to infants born of $\mathrm{HBsAg}-\mathrm{HBeAg}$ positive mothers at birth, susceptible individuals with an acute exposure to infectious HBV-containing material or orthotopic liver transplant patients with chronic HBV-related liver disease (Beasley et al., 1983; McGory et al., 1996; Terrault et al., 1996; Sawyer et al., 1998). However, the currently available HBIG is not an ideal source of antibody due to the limited availability and low specific activity. Therefore, mAbs specific to the surface antigens of HBV would be a good alternative for the immunoprophylaxis of HBV infection.

The HBV envelope contains three related surface glycoproteins called the large (L), middle (M), and small (S) proteins. All these proteins are the product of a single open reading frame that is divided into the preS1, preS2, and $S$ regions (Heermann et al., 1984). The $S$ protein is encoded by the $S$ region. The M protein contains the preS2 and $S$ regions, and the $L$ protein contains the preS1, preS2, and $S$ regions. The $S$ protein carries the common a determinant and two sets of mutually exclusive subtype determinants $d / y$ and $w / r$, and thus the four major subtypes (adw, adr, ayw, and ayr) of the HBV surface antigen (HBsAg) denote the antigenic types of HBV (Courouce et al., 1983). The serotypes have an unequal distribution worldwide. The $y$ and $r$ determinant are absent from Far-East Asia and from Africa, respectively. The common a determinant of the $S$ protein was shown to elicit virus- neutralizing and protective antibodies (Bhatnager et al., 1982; Dreesman et al., 1982; Heermann et al., 1987). In addition, a single mAb specific to the common a determinant of the $S$ protein was demonstrated to have virus-neutralizing activity in chimpanzees or 
humans (Ogata et al., 1993; Heijtink et al., 1999; Eren et al., 2000; Galun et al., 2002). However, since the escape mutants of the common a determinant have arisen (Fujii et al., 1992; McMahon et al., 1992; Kohno et al., 1996; Terrault et al., 1998), development of more new anti-HBV neutralizing antibodies would be beneficial in the immunoprophylaxis of HBV infection.

Murine mAbs are easy to produce, but their therapeutic use in humans is limited because of human anti-mouse antibody (HAMA) response during treatment (Shawler et al., 1985). To circumvent the problem, humanized antibodies have been constructed by grafting the mouse complementarity determining regions (CDRs), which form antigen-binding pocket, onto homologous human antibody variable regions, while retaining some murine residues in framework regions (FRs) that are predicted to influence the conformation of CDRs (Riechmann et al., 1988; Queen et al., 1989; Nakatani et al., 1994). Several humanized antibodies are in clinical use in humans (Reichert et al., 2005).

Previously, we generated a murine mAb, H67 that recognizes the a determinant on the $S$ protein (Ryu et al., 1994) and subsequently developed a humanized antibody (HuS10) of which affinity is same as that of the parental murine mAb (Ryu et al., 1996). The antibody showed neutralizing activity against both the adr and ayw subtypes of the virus in an in vitro infection of adult human hepatocyte primary culture by HBV (Ryu et al., 1996). In this study, we demonstrated in vivo HBV-neutralizing activity of HuS10 in chimpanzees.

\section{Materials and Methods}

\section{Cell culture}

The dihydrofolate reductase (DHFR)-deficient Chinese hamster ovary (CHO) cell line, DG44 was used for stable expression of the humanized antibody. The DG44 cells were grown at $5 \% \mathrm{CO}_{2}, 37^{\circ} \mathrm{C}$ in DMEM/F12 (GIBCO/BRL) supplemented with hypoxanthine $(10 \mathrm{mg} / \mathrm{l})$, thymidine $(10 \mathrm{mg} / \mathrm{l})$, glycine (50 mg/l), glutamine (587 mg/l), glucose (4.5 mg/l), $10 \%$ FBS, and Antibiotics-Antimycotics (GIBCO/ $B R L)$.

\section{Production of humanized antibody}

The humanized heavy and light chain expression plasmids were cotransfected into DHFR-deficient $\mathrm{CHO}$ cell line (DG44), and stably transformed cell lines were selected in a medium containing G418 $(550 \mu \mathrm{g} / \mathrm{ml})$ and subsequently subjected to metho- trexate (MTX) selection for gene amplification, as described previously (Ryu et al., 1996). A recombinant $\mathrm{CHO}$ cell line secreting the humanized antibody was grown in serum free medium (CHO-SSFMII, GIBCO/BRL), and the culture supernatant was subjected to affinity chromatography on Protein G-Sepharose 4B column (Pharmacia), as described previously (Ryu et al., 1996).

\section{Chimpanzee study}

Two chimpanzees (CA0218 and CA0215), which were born in a breeding colony in the United States (White Sands Research Center, Alamogordo, NM) under a Food and Drug Administration contract, were used in this study. These animals had not been previously inoculated with any HBV-containing materials and were seronegative for all HBV-associated serological markers. The study chimpanzee (CA0215) was intravenously administered with purified HuS10 at a dose of $5 \mathrm{mg} / \mathrm{kg}$ (body weight), while the control animal (CA0218) was administered with PBS. Three days later, $10^{-5}$ dilution of human sera containing adr subtype of wild type HBV (kindly provided by Dr. R. H. Purcell at NIH), whose end-point infectivity titer in chimpanzees was previously determined to be $10^{-8}$ (Tabor et al., 1983), was inoculated intravenously into the animals. Serum samples taken from the chimpanzees were monitored for levels of the humanized antibody HuS10, HBsAg, and antibodies to $\mathrm{HBcAg}$ and $\mathrm{HBsAg}$ as well as for serum chemistry, hematology, and urinanalysis. Serological assays of the HBV antigens and anti-HBV antibodies were carried out using commercial kits (Abbott Laboratories, North Chicago, IL) in WSRC.

\section{Results}

\section{In vivo HBV-neutralizing activity of humanized antibody HuS10 in chimpanzees}

Previously, we generated a murine mAb $(\mathrm{H} 67)$ that binds to both adr and ayw subtypes of HBsAg, and subsequently constructed a humanized antibody (HuS10) whose affinity $\left(5 \times 10^{8} \mathrm{M}^{-1}\right)$ is same as that of the parental murine mAb (Ryu et al., 1996). HuS10 neutralized both the adr and ayw subtypes of HBV in an in vitro infection of adult human hepatocyte primary culture by HBV (Ryu et al., 1996).

To evaluate the virus-neutralizing activity of HuS10 in chimpanzees, a stable $\mathrm{CHO}$ cell line expressing HuS10 was grown in serum-free medium and the antibody was purified from the culture supernatant by an affinity chromatography on Pro- 
Table 1. The analysis of HBV infection in the serum of the control and the study chimpanzees.

A. Detection of $\mathrm{HBsAg}$

\begin{tabular}{|c|c|c|c|c|c|c|c|c|c|c|c|c|c|c|c|}
\hline & & & \multicolumn{13}{|c|}{ Study week } \\
\hline & & & $1-13$ & 14 & 15 & 16 & 17 & 18 & 19 & 20 & $21-29$ & 30 & 34 & 37 & $40-52$ \\
\hline I & Control & CA0218 & $\mathrm{N}$ & $\mathrm{R}$ & $\mathrm{R}$ & $\mathrm{R}$ & $\mathrm{R}$ & $R$ & $\mathrm{R}$ & $R$ & $\mathrm{~N}$ & $\mathrm{~N}$ & $\mathrm{~N}$ & $\mathrm{~N}$ & $\mathrm{~N}$ \\
\hline II & HuS10 & CA0215 & $\mathrm{N}$ & $\mathrm{N}$ & $\mathrm{N}$ & $\mathrm{N}$ & $\mathrm{N}$ & $\mathrm{N}$ & $\mathrm{N}$ & $\mathrm{N}$ & $\mathrm{N}$ & $\mathrm{N}$ & $\mathrm{R}$ & $\mathrm{R}$ & $\mathrm{N}$ \\
\hline
\end{tabular}

Titers were determined using a commercial kit (Abbott Laboratories). The positivity was defined as the absorbance of the negative control mean plus the factor of 0.05 according to the manufacturer's instruction manual. $\mathrm{N}=$ Non-reactive and $\mathrm{R}=$ Positive reactivity.

B. Detection of anti-HBc antibodies

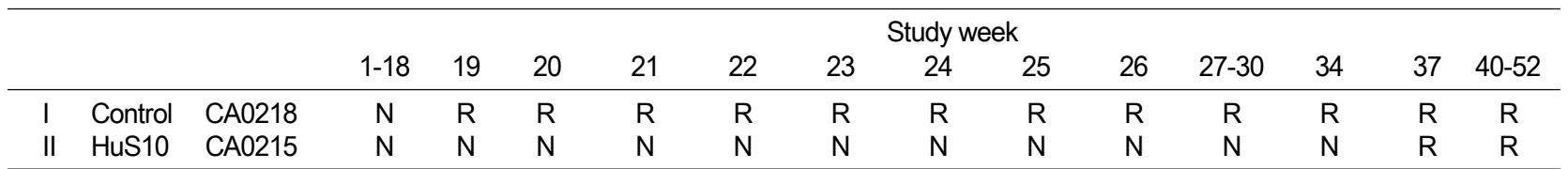

Titers were determined using a commercial kit (Abbott Laboratories). Specimens with absorbance values equal to or lower than the cutoff value are considered reactive according to the manufacturer's instruction manual. Cutoff value was determined using the following equation: $0.4(\mathrm{NCx})+0.6(\mathrm{PCx})=\mathrm{Cutoff}$ Value. $\mathrm{N}=$ Non-reactive and $\mathrm{R}=$ Positive reactivity.

C. Determination of anti-HBs antibodies

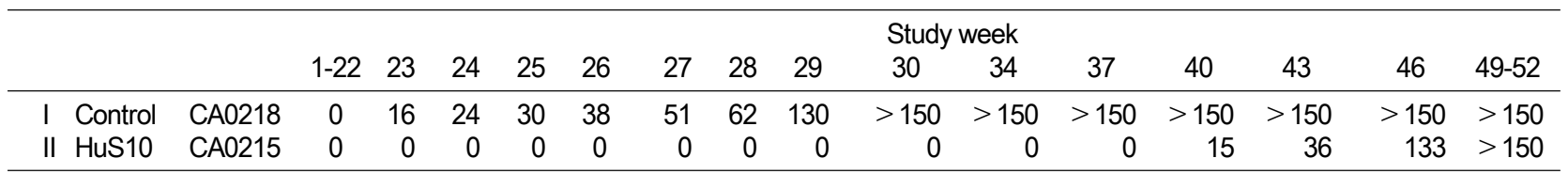

Titers were determined using a commercial kit (Abbott Laboratories). Result of $<5$ was considered 0 .

Table 2. The titers of administered HuS10 in chimpanzees.

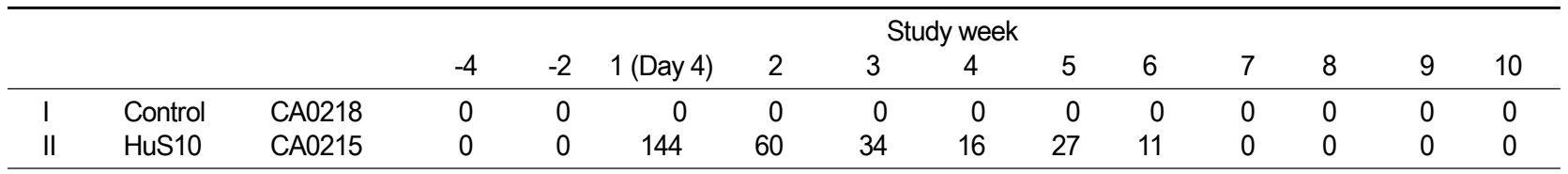

Titers were determined using a commercial kit (Abbott Laboratories). Result of $<5$ was considered 0 .

tein G-Sepharose, as described in the Materials and Methods. The purified antibody was $99 \%$ pure and free of endotoxin and pyrogen, and did not exhibit abnormal toxicity (data not shown).

Two chimpanzees, one study chimpanzee and one control chimpanzee, were used in this study. The study chimpanzee (CA0215) was intravenously administered with the humanized antibody (5 $\mathrm{mg} / \mathrm{kg}$ ) and three days later the animals were challenged with $10^{-5}$ dilution of human sera containing adr subtype of HBV, whose end-point infectivity titer in chimpanzees had been determined to be $10^{-8}$ (Tabor et al., 1983). The control chimpanzee (CA0218) was only challenged with the same dose of the virus. The course of HBV infection in the chimpanzees was weekly monitored by serological and biochemical analyses of the sera for $1 \mathrm{yr}$ (Table 1). Also, the titers of the administered humanized antibody HuS10 in the sera of chimpanzees were measured for the first
10 weeks (Table 2).

In the case of the control chimpanzee, serum HBsAg became positive from the $14^{\text {th }}$ to $20^{\text {th }}$ week. Also, actively acquired serum anti-HBc and antiHBs antibodies appeared from the $19^{\text {th }}$ and $23^{\text {rd }}$ week, respectively and remained at elevated level through the end-point of this experiment. In contrast, in the case of the study chimpanzee, serum HBsAg became positive from the $34^{\text {th }}$ to $37^{\text {th }}$ week, while actively acquired serum anti- $\mathrm{HBc}$ and antiHBs antibodies appeared from the $37^{\text {th }}$ and $40^{\text {th }}$ week, respectively and remained at elevated level through the end-point of this experiment. The courses of HBV infection in the chimpanzees are summarized in Figure 1. The results indicate that the humanized antibody neutralized the virus in vivo and thus protected the chimpanzee from HBV infection.

The HuS10 antibody administered in the study chimpanzee was detected in the serum for 6 
A

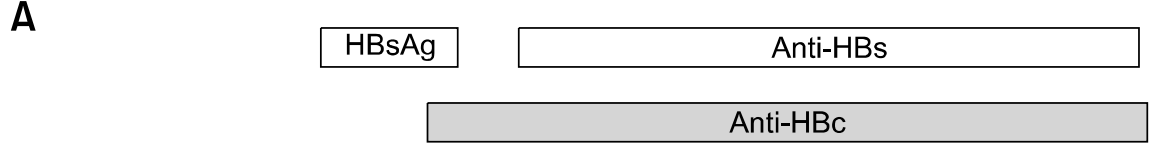

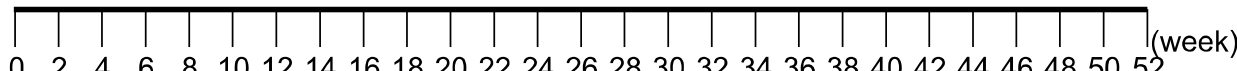

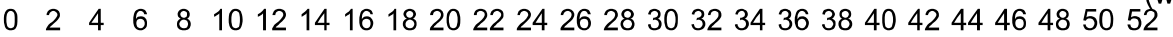

B

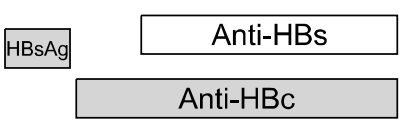

Figure 1. The course of HBV infection showing the appearance of $\mathrm{HBsAg}$ and anti-HBV antibodies in the serum of the control chimpanzee (A) and the study chimpanzee (B).

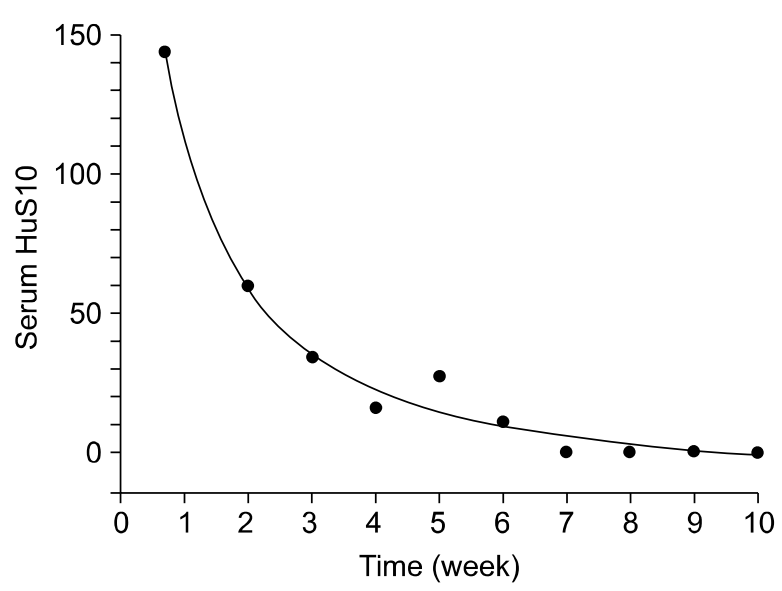

Figure 2. The serum levels of the administered HuS10 in the study chimpanzee. The study chimpanzee (CA0215) was intravenously administered with purified HuS10 at a dose of $5 \mathrm{mg} / \mathrm{kg}$ (body weight) and three days later, adr subtype of wild type HBV was inoculated intravenously. The titer of HuS10 was measured using the commercial kit (Abbott Laboratories).

weeks (Table 2). The humanized antibody had a half-life of approximately 8 days in the challenged chimpanzee (Figure 2), which is shorter compared to that (2-3 weeks) of human IgG in unchallenged chimpanzees or humans (Reichert et al., 2005). This may be because the humanized antibody molecules bound to the challenged HBV and were eliminated from the blood of the challenged chimpanzee.

\section{Discussion}

For the prevention or post-exposure prophylaxis of HBV infection, human mAbs specific to the common a determinant of the $S$ protein have been developed and their HBV-neutralizing activities were demonstrated in chimpanzees or humans (Ogata et al., 1993; Heijtink et al., 1999; Eren et al., 2000; Galun et al., 2002). However, mostly their HBV-neutralizing activities were demonstrated against only ayw subtype. In addition, considering that the common a determinant region of the $S$ protein has highly conformational structure and the escape mutants of the common a determinant have arisen (Fujii et al., 1992; McMahon et al., 1992; Bruce and Murray, 1995; Howard, 1995; Kohno et al., 1996; Keum et al., 1998; Terrault et al., 1998), development of more new HBV-neutralizing antibodies is beneficial in the immunoprophylaxis of HBV infection. In this study, we demonstrated the HBV-neutralizing activity of the humanized antibody (HuS10) against the adr subtype (Figure 1). This humanized antibody may be useful in the immunoprophylaxis of HBV infection in the Far-East Asia, where the ad subtype is endemic.

\section{Acknowledgments}

We thank Dr. Robert Purcell at NIH for providing the wild type HBV and Taehyoung Kwon for editorial assistance. This work was supported by Ministry of Health and Welfare Grant A050260 and Korea Research Institute of Bioscience and Biotechnology Research Initiative Program Grant KGM3100612.

\section{References}

Beasley RP, Hwang LY, Lee CY, Lan CC, Roan CH, Huang $F Y$, Chen CL. Prevention of perinatally transmitted hepatitis $B$ virus infection with hepatitis $B$ immune globulin and hepatitis B vaccine. Lancet 1983;2:1099-102

Bhatnager PK, Papas E, Blum HE, Milich DR, Nitecki D, Kareb MJ, Vyas GN. Immune response to synthetic peptide analogues of HBsAg specific for the a detertminant. Proc Natl Acad Sci 1982;79:4723-27

Bruce SA, Murray K. Mutations of some critical amino acids residues in the hepatitis $B$ virus surface antigen. J Med Virol 1995;46:157-61

Courouce AM, Lee H, Drouet J, Canavaggio M, Soulier J. Monoclonal antibodies to HBsAg: a study of their specificities for eight different HBsAg subtypes. Dev Biol Stand 1983;54: 527-34 
Dreesman GR, Sanchez Y, Ionescu-Matiu I, Sparrow JT, Six HR, Peterson DL, Hollinger FB, Melnick JL. Antibody to hepatitis B surface antigen after a single inoculation of uncoupled synthetic HBsAg peptides. Nature (London) 1982;295:158-60

Eren R, llan E, Nussbaum O, Lubin I, Terkieltaub D, Arazi Y, Ben-Moshe O, Kitchinzky A, Berr S, Gopher J, Zauberman A, Galun E, Shouval D, Daudi N, Eid A, Jurim O, Magnius LO, Hammas B, Reisner Y, Dagan S. Preclinical evaluation of two human anti-hepatitis $B$ virus (HBV) monoclonal antibodies in the HBV-trimera mouse model and in HBV chronic carrier chimpanzees. Hepatology 2000;32:588-96

Fujii HK, Moriyama K, Sakamoto N, Kondo T, Yasuda K, Hiraizumi Y, Yamazaki M, Sakaki Y, Okochi K, Nakajima E. Gly145 to Arg substitution in HBs antigen of immune escape mutant of hepatitis B virus. Biochem Biophys Res Commun 1992;184:1152-7

Galun E, Eren R, Safadi R, Ashour Y, Terrault N, Keeffe EB, Matot E, Mizrachi S, Terkieltaub D, Zohar M, Lubin I, Gopher J, Shouval D, Dagan S. Clinical evaluation (phase I) of a combination of two human monoclonal antibodies to HBV: safety and antiviral properties. Hepatology 2002;35:673-9

Heermann N, Goldmann U, Schwartz W, Seyffarth T, Baumgarten H, Gerlich W. Large surface proteins of hepatitis $B$ virus containing the pre-S sequence. J Virol 1984;52: 396-402

Heermann, Kruse F, Seifer M, Gerlich WH. Immunogenicity of the gene $S$ and pre-S domains in hepatitis $B$ virions and HBsAg filaments. Intervirology 1987;28:14-25

Heijtink R, Paulij W, van Bergen P, van Roosmalen M, Rohm $D$, Eichentopf B, Muchmore E. In vivo activity of a mixture of two human monoclonal antibodies (anti-HBs) in a chronic hepatitis B virus carrier chimpanzee. J Gen Virol 1999;80: 1529-35

Howard CR. The structure of hepatitis B envelope and molecular variants of hepatitis B virus. J Viral Hepatitis 1995;2:165-70

Keum WK, Kim JY, Kim JY, Chi SG, Woo HJ, Kim SS, Ha J, Kang I. Heterogeneous HBV mutants coexist in Korean hepatitis B patients. Exp Mol Med 1998;30:115-22

Kohno H, Inoue T, Tsuda F, Okamoto H, Akahane Y. Mutations in the envelope gene of hepatitis $B$ virus variants co-occurring with antibody to surface antigen in sera from patients with chronic hepatitis B. J Gen Virol 1996;77:182531

McGory RW, Ishitani MB, Oliveira WM, Stevenson WC, McCullough CS, Dickson RC, Caldwell SH, Pruett TL. Improved outcome of orthotopic liver transplantation for chronic hepatitis cirrhosis with aggressive passive immunization. Transplantation 1996;61:1358-64

McMahon G, Ehrlich PH, Moustafa ZA, McCarthy LA, Dottavio D, Tolpin MD, Nadler PI, Ostberg L. Genetic alterations in the gene encoding the major HBsAg: DNA and immunological analysis of recurrent HBsAg derived from monoclonal antibody-treated liver transplant patients. Hepatology 1992;15:757

Nakatani T, Lone YC, Yamakawa J, Kanaoka M, Gomi H, Wijdenes J, Noguchi H. Humanization of mouse anti-human IL-2 receptor antibody B-B10. Protein Eng 1994;7:435

Ogata N, Ostberg L, Ehrlich PH, Wong DC, Miller RH, Percell $\mathrm{RH}$. Markedly prolonged incubation period of hepatitis $\mathrm{B}$ in a chimpanzee passively immunized with a human monoclonal antibody to the $\alpha$ determinant of hepatitis $B$ surface antigen. Proc Natl Acad Sci USA 1993;90:3014-8

Queen C, Schneider WP, Selick HE, Payne PW, Landolfi NF, Duncan JF,Avdalovic NM, Levitt M, Junghans RP, Waldman TA. A humanized antibody that binds to the interleukin 2 receptor. Proc Natl Acad Sci USA 1989;86:10029-33

Reichert JM, Rosensweig CJ, Faden LB, Dewitz MC. Monoclonal antibody successes in the clinic. Nature Biotechnology 2005;23:1073-8

Riechmann L, Clark M, Waldmann H, Winter G. Reshaping human antibodies for therapy. Nature 1988;32:323-7

Ryu CJ, Jin BR, Chung HK, Han MH, Hong HJ. Cloning and characterization of cDNAs coding for heavy and light chains of a monoclonal antibodies specific for the cDNAs coding for heavy and light chains of a monoclonal antibodies specific for the S antigen of hepatitis B virus. Gene 1994;1244:313-4

Ryu CJ, Padlan EA, Jin BR, Yoo OJ, Hong HJ. A humanized antibody with specificity for Hepatitis B surface antigen. Human Antibodies and Hybridomas 1996;7:113-22

Sawyer RG, McGory RW, Gaffey MJ, McCullough CC, Shephard BL, Houlgrave CW, Ryan TS, Kuhns M, McNamara A, Caldwell SH, Abdulkareem A, Pruett TL. Improved clinical outcomes with liver transplantation for hepatitis B-induced chronic liver failure using passive immunization. Ann Surg 1998;227:841-50

Shawler DL, Bartholomew RM, Smith LM, Dillman RO. Human immune response to multiple injections of murine monoclonal IgG. J Immunol 1985;135:1530-5

Tabor E, Purcell RH, London WT, Gerety RJ. Use of and interpretation of results using inocula of hepatitis $B$ virus with known infectivity titers. J Infect Dis 1983;147:531-4

Terrault NA, Zhou S, Combs C, Hahn JA, Lake JR, Roberts JP, Ascher NL, Wright TL. Prophylaxis in liver transplant recipients using a fixed dosing schedule of hepatitis $B$ immunoglobulin. Hepatology 1996;24:1327-33

Terrault NA, Zhou S, McCory RW, Pruett TL, Lake JR, Roberts JP, Ascher NL, Wright TL. Incidence and clinical consequences of surface and polymerase gene mutations in liver transplant recipients on hepatitis $B$ immunoglobulin. Hepatology 1998;28:555-61

Tiollais P, Buendia MA. Hepatitis B virus. Scientific American $1991 ; 264: 48-54$ 